\title{
E2F-1 targets miR-519d to regulate the expression of the ras homolog gene family member $\mathrm{C}$
}

\author{
Xiu-Bo Sang ${ }^{1}$, Zhi-Hong Zong ${ }^{2}$, Li-Li Wang ${ }^{1}$, Dan-Dan Wu ${ }^{1}$, Shuo Chen ${ }^{1}$, Bo-Liang \\ Liu ${ }^{1}$, Yang Zhao ${ }^{1}$ \\ ${ }^{1}$ Department of Gynecology, The First Affiliated Hospital of China Medical University, Shenyang 110001, P. R. China \\ ${ }^{2}$ Department of Biochemistry and Molecular Biology, College of Basic Medicine, China Medical University, Shenyang 110001, \\ P. R. China \\ Correspondence to: Yang Zhao, email: yida.zhaoyang@163.com
}

Keywords: ovarian carcinoma, E2F1, microRNA-519d, RhoC, tumorigenesis and progression

Received: May 20, $2016 \quad$ Accepted: January 16, $2017 \quad$ Published: January 27, 2017

\section{ABSTRACT}

E2F1 (E2F transcription factor 1) can act as a tumor suppressor or oncogene. We report the molecular mechanism of E2F1 in ovarian carcinoma tumorigenesis and progression. E2F1 expression levels in ovarian carcinoma tissue were examined by immunohistochemistry. After E2F1 plasmid transfection and E2F1-microRNA519d (miR-519d)/si-RhoC (Ras homolog gene family member C) co-transfection, ovarian cancer cell phenotypes and the related molecules were examined in vitro and in vivo. E2F1 was overexpressed in type I and type II ovarian carcinoma as compared to normal ovary tissues and normal fallopian tube tissues, respectively. E2F1 overexpression promoted cell proliferation, G1-S progression, survival, migration, and invasion in vitro; miR-519d or siRhoC co-transfection reversed E2F1 oncogenic effects. E2F1 overexpression promoted tumor growth in vivo; miR-519d overexpression inhibited it. E2F1 overexpression increased RhoC, Bcl-2, cyclin D1, survivin, MMP2 (matrix metalloproteinase 2), MMP9, STAT3 (signal transducer and activator of transcription 3 ), and HuR (ELAV-like RNA-binding protein 1) expression; miR-519d overexpression decreased their expression. E2F1 downregulated miR-519d directly and miR-519d downregulated RhoC directly. Conversely, miR-519d directly downregulated E2F1, There is a direct repressive regulatory loop between E2F1 and miR-519d. We provide evidence that E2F1/miR-519d/RhoC is a promising signaling pathway for diagnosing and treating ovarian carcinoma.

\section{INTRODUCTION}

Epithelial ovarian carcinoma is the most lethal gynecological malignancy, and has consistently low 5 -year relative survival rates [1-5]. Difficult early diagnosis and frequent recurrence and metastasis lead to the high mortality rate of epithelial ovarian carcinoma. Exploring the underlying molecular mechanisms of epithelial ovarian carcinoma is essential for developing effective diagnostic and treatment strategies.

E2F transcription factor family members regulate the cell cycle, proliferation, apoptosis, and differentiation. Aberrant $E 2 F$ gene expression is frequently documented in many cancers [6-10]. Among them, E2F1 (E2F transcription factor 1) has drawn much attention because of its complex and diverse functions in different cancers [11-24]. E2F1 suppresses gastric cancer by downregulating Bcl-2, cyclin D1, and survivin [17], and inhibits Hodgkin lymphoma by upregulating p53 expression [25]. Conversely, it plays an oncogenic role by enhancing matrix metalloproteinase 9 (MMP9) transcription during invasion and metastasis in small cell lung cancer [28] and by activating MMP2 and MMP9 in local and vascular infiltration in clear cell renal cell carcinoma [29]. E2F1 expression is increased in ovarian carcinoma tissues, and it is believed that E2F1 is a promoter of the development of ovarian carcinoma [26-30]. However, the exact underlying molecular mechanism remains elusive. 


\section{RESULTS}

\section{The correlation between E2F1 expression and ovarian carcinoma pathogenesis and aggressiveness}

Immunohistochemical analysis of the clinical relevance of E2F1 expression in ovarian carcinoma showed that E2F1 expression was statistically significantly elevated in type I tumors (Table 1) compared to normal ovarian tissues (Figure 1A, 1D) and was positively associated with International Federation of Gynecology and Obstetrics (FIGO) stage I-II and III-IV disease. E2F1 expression was also significantly elevated in type II tumors (Table 2) compared to normal fallopian tube tissues (Figure 1B, 1E). The findings suggest that E2F1 has potent oncogenic effects in ovarian carcinoma (Figure 1C, 1F) of different type and origin.

\section{Effects of E2F1 on ovarian carcinoma in vitro and in vivo}

E2F1 mRNA and protein expression levels in SKOV3, HO8910, ES-2, CAOVR3, OVCAR3, A2780 and A2780PTX cells were examined by reverse transcriptionPCR (RT-PCR) and western blotting (Figure 2A, 2B, $P<0.05)$, respectively. E2F1 plasmid and E2F1 short interfering RNA (siRNA) were transfected into the A2780 and OVCAR3 cell lines, which were selected for their intermediate $E 2 F 1$ expression, which allowed us to stably upregulate $E 2 F 1$ expression via $\mathrm{E} 2 \mathrm{~F} 1$ plasmid transfection (Figure 2C, 2D, $P<0.05$ ) and to downregulate $E 2 F 1$ expression using the E2F1 siRNA (Figure 2E, 2F, $P<0.05)$. Following the transfection, we analyzed E2F1 levels by RT-PCR and western blot.

The tetrazolium (MTT), cell cycle, apoptosis, wound healing, and cell invasion assays demonstrated that cells transfected with E2F1 plasmid had faster growth (Figure 3A, $P<0.05$ ), promoted $\mathrm{G} 1-\mathrm{S}$ progression (Figure 3B, $P<0.05$ ), decreased apoptosis (Figure 3C, $P<0.05$ ), and increased migration (Figure $3 \mathrm{D}, P<0.05$ ) and invasive ability (Figure 3E, $P<0.05$ ). In contrast, E2F1 siRNA caused severe growth retardation (Figure 3F, $P<0.05$ ), increased the number of cells in G1 phase and reduced the number of cells in S phase (Figure 3G, $P<0.05$ ), induced higher levels of apoptosis (Figure $3 \mathrm{H}$, $P<0.05$ ), and reduced cell migration (Figure 3I, $P<0.05$ ) and invasive ability (Figure $3 \mathrm{~J}, P<0.05$ ) as compared to the control and mock-transfected cells.

In the nude mouse xenograft model, mice injected with cells stably transfected E2F1 plasmid had a dramatic induction of tumor size (Figure $3 \mathrm{~K}, P<0.05$ ) and faster tumor growth than the control mice (Figure $3 \mathrm{~L}, 3 \mathrm{M}$, $P<0.05$ ), suggesting that $\mathrm{E} 2 \mathrm{~F} 1$ promotes tumorigenesis and growth.

\section{E2F1 targets the miR-519d promoter directly,} and miR-519d targets E2F1 mRNA directly

We searched target prediction websites (UCSC Genome Browser Home, http://genome.ucsc.edu/; JASPAR database, http://jaspar.genereg.net/) and predicted that the $m i R-519 d$ promoter contains an E2F1 binding site. E2F1 transfection repressed miR-519d mRNA expression (Figure 4A, $P<0.05$ ), while silencing E2F1 promoted it (Figure 4B, $P<0.05$ ). The dual luciferase reporter assay showed that miR-519d-luciferase reporter plasmid and E2F1 plasmid co-transfection in HEK293 cells significantly reduced luciferase activity (Figure 4C, $P<0.05$ ), with both mutant and control groups showing no significant changes in luciferase activity. These results demonstrate that E2F1 directly binds the miR-519d promoter to decrease miR-519d expression.

The microRNA.org website (http://microRNA.org) predicted that the E2F1 mRNA 3' untranslated region ( $3^{\prime}$ UTR) contained miR-519d binding sites (Figure 4D, $P<0.05)$. MiR-519d transfection downregulated E2F1 mRNA expression (Figure 4E, $P<0.05$ ), and there was fold reduction in the luciferase activity of HEK293 cells co-transfected with E2F1-luciferase reporter plasmid and miR-519d mimic when compared with the mutant and control groups (Figure 4F, $P<0.05$ ), which suggests that miR-519d directly downregulates E2F1.

The above findings reveal that a direct repressive regulatory loop exists between E2F1 and miR-519d.

\section{MiR-519d inhibits ovarian carcinoma and downregulates RhoC directly}

Western blot showed that miR-519d transfection in ovarian carcinoma cells downregulated RhoC (Ras homolog gene family member C), Bcl-2, cyclin D1, survivin, MMP2, MMP9, STAT3 (signal transducer and activator of transcription 3), and HuR (ELAV-like RNAbinding protein 1) expression (Figure $5 \mathrm{~A}, P<0.05$ ). No changes were observed in $\mathrm{p} 53$ expression. This suggests that miR-519d has suppressive effects on ovarian carcinoma by downregulating RhoC, Bcl-2, cyclin D1, survivin, MMP2, MMP9, STAT3 and HuR expression.

A target prediction website (http://microRNA.org) revealed that miR-519d binds the RhoC mRNA 3' UTR region (Figure 5B). Transfecting miR-519d mimic into A2780 and OVCAR3 cell significantly decreased $R h o C$ mRNA (Figure 5C, $P<0.05$ ).

We generated a luciferase reporter gene containing the human $R h o C$ mRNA 3' UTR predicted to have potential miR-519d binding sites. Co-transfecting HEK293 cells with RhoC-luciferase reporter plasmid plus miR-519d mimic significantly reduced luciferase activity (Figure 5D, $P<0.05)$. Furthermore, luciferase activity was fully 
Table 1: Relationship between E2F1 expression and clinicopathological features of Type I ovarian carcinomas

\begin{tabular}{|c|c|c|c|c|c|c|c|}
\hline \multirow{2}{*}{ Clinicopathological feature } & \multicolumn{4}{|c|}{$\operatorname{E2F1}(-=0,+=1,++=2,+++=3)$} & \multirow{2}{*}{ Total } & \multirow{2}{*}{ PR (\%) } & \multirow{2}{*}{$P$ valu } \\
\hline & $\mathbf{0}$ & 1 & 2 & 3 & & & \\
\hline \multicolumn{8}{|l|}{ The pathology types } \\
\hline Normal ovarian tissues & 16 & 1 & 0 & 0 & 17 & 5.88 & 0.0027 \\
\hline Type I tumors & 32 & 21 & 6 & 0 & 59 & 45.76 & \\
\hline FIGO stages & & & & & & & 0.0005 \\
\hline I-II & 27 & 9 & 2 & 0 & 38 & 28.95 & \\
\hline III-IV & 5 & 12 & 4 & 0 & 21 & 76.19 & \\
\hline
\end{tabular}

$\overline{\mathrm{PR}}=$ positive rate; Bold means $P<0.05$.

Immunohistochemical analysis of the clinical relevance of E2F1 expression in ovarian carcinoma showed that E2F1 expression was statistically significantly elevated in type I tumors compared to normal ovarian tissues and was positively associated with International Federation of Gynecology and Obstetrics (FIGO) stage I-II and III-IV disease.

restored in the mutant and control groups, demonstrating that $R h o C$ mRNA is a direct target of miR-519d.

The nude mouse xenograft model showed that mice injected with cells stably expressing miR-519d had obviously reduced tumor size (Figure 5E, $P<0.05$ ) and tumor growth than the control mice (Figure $5 \mathrm{~F}, 5 \mathrm{G}$, $P<0.05)$. Immunohistochemistry showed that E2F1 and $\mathrm{RhoC}$ expression were downregulated in the tumor xenograft tissues of the miR-519d group as compared to the control (Figure 5H).
These results demonstrate that miR-519d directly decreases RhoC and downregulates the expression of Bcl-2, cyclin D1, survivin, MMP2, MMP9, STAT3, and HuR to suppress ovarian carcinoma.

\section{Effects of E2F1 on ovarian carcinoma cell genotype}

E2F1 overexpression increased RhoC, Bcl-2, cyclin D1, survivin, MMP2, MMP9, STAT3, and
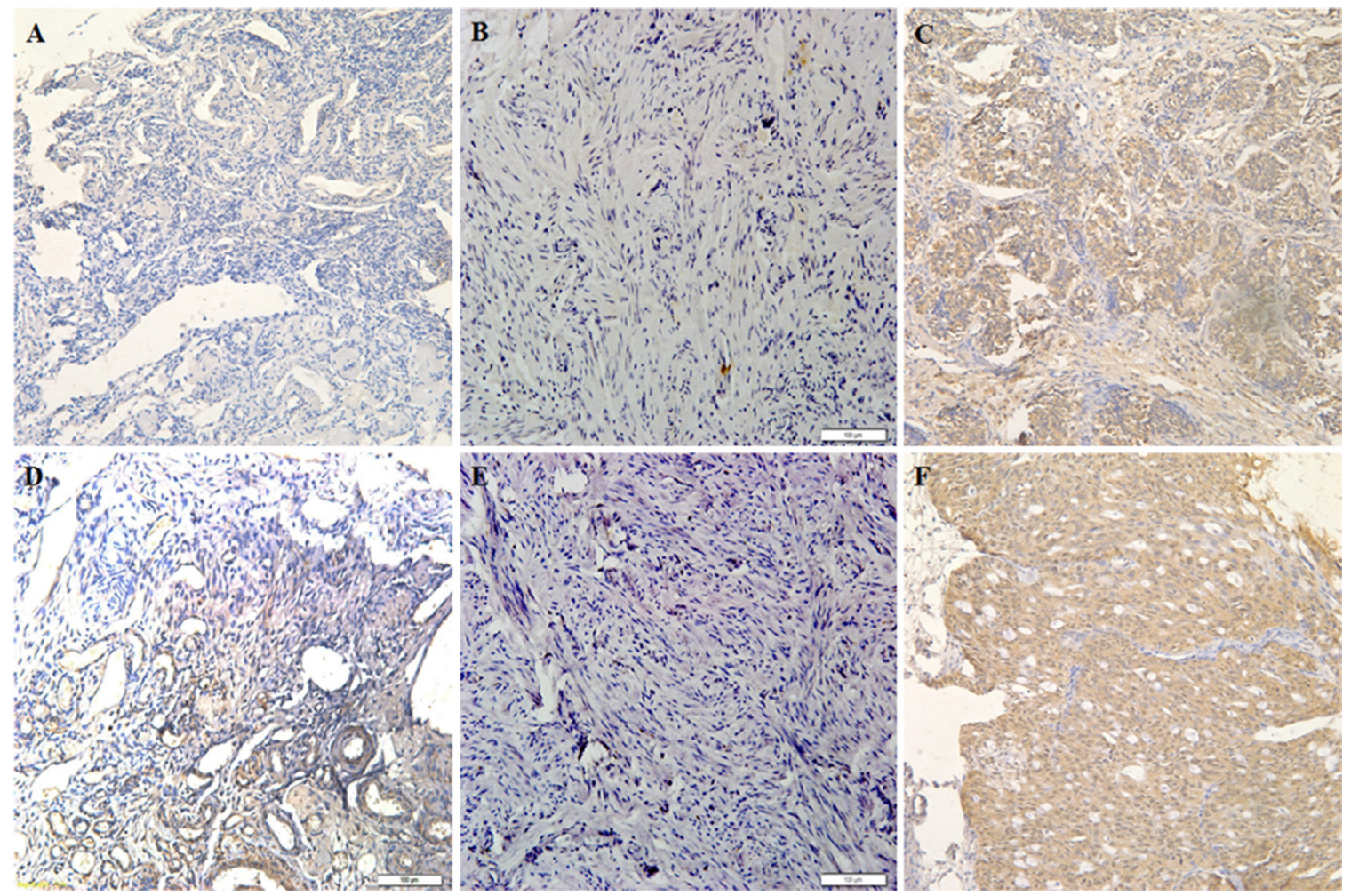

Figure 1: E2F-1 expression is correlated with pathogenesis and aggressiveness of ovarian carcinoma. E2F-1 expression in normal ovarian tissue (A and $\mathbf{D})$ oviduct tissues $(\mathbf{B}$ and $\mathbf{E})$ and ovarian carcinoma tissues $(\mathbf{C}$ and $\mathbf{F})$ which was detected by immunohistochemistry. 
Table 2: Relationship between E2F1 expression and clinicopathological features of Type II ovarian carcinomas

\begin{tabular}{lccccccc}
\hline \multirow{2}{*}{ Clinicopathological feature } & \multicolumn{9}{c}{ E2F1 $(-=\mathbf{0},+=\mathbf{1},++=\mathbf{2},+++=\mathbf{3})$} & Total & PR (\%) & P value \\
\hline The pathology types & $\mathbf{0}$ & $\mathbf{1}$ & $\mathbf{2}$ & $\mathbf{3}$ & & \multicolumn{2}{c}{$\mathbf{0 . 0 0 0 6}$} \\
Normal fallopian tubes & 21 & 2 & 0 & 0 & 23 & 8.70 & \\
Type II tumors & 50 & 38 & 7 & 1 & 96 & 47.92 & \\
FIGO stages & & & & & & & 0.4717 \\
II & 8 & 9 & 1 & 0 & 18 & 55.56 & \\
III-IV & 42 & 29 & 6 & 1 & 78 & 46.15 & \\
\hline
\end{tabular}

PR = positive rate; Bold means $P<0.05$.

Immunohistochemical analysis of the clinical relevance of E2F1 expression in ovarian carcinoma showed that E2F1 expression was significantly elevated in type II tumors compared to normal fallopian tube tissues.

HuR protein and mRNA expression (Figure 6A, 6B, $P<0.05$ ); Silencing $E 2 F 1$ decreased RhoC, Bcl-2, cyclin D1, survivin, MMP2, MMP9, STAT3, and HuR protein and mRNA expression (Figure $6 \mathrm{C}, 6 \mathrm{D}, P<0.05$ ). No changes were observed in $\mathrm{p} 53$ expression.

The immunohistochemistry assay showed that E2F1 and $\mathrm{RhoC}$ expression were upregulated in the tumor xenograft tissue from nude mice of the E2F1 group when compared to the control group (Figure $6 \mathrm{E}, P<0.05$ ). The findings support the premise that $\mathrm{E} 2 \mathrm{~F} 1$ promotes ovarian carcinogenesis and growth by upregulating the expression of $\mathrm{RhoC}$ and $\mathrm{Bcl}-2$, cyclin D1, survivin, MMP2, MMP9, STAT3, and HuR.

MiR-519d triggered cellular senescence by repressing $\mathrm{HuR}$ expression. The senescence detection kit showed that silencing E2F1 increased SA- $\beta$-gal (senescence-associate $\beta$-galactosidase) activity and triggered senescence as compared to the control groups (Figure 6F, $P<0.05$ ). The data indicate that silencing E2F1 directly targeted miR-519d to downregulate HuR, inducing cellular senescence.

\section{Effects of E2F1 and miR-519d co-transfection on ovarian carcinoma cells}

A2780 and OVCAR3 cells were co-transfected with E2F1 plasmid and miR-519d mimic or with E2F1 siRNA and miR-519d inhibitor. The MTT, cell cycle, apoptosis, wound healing, and cell invasion assays showed that E2F1 plasmid and miR-519d mimic co-transfection reversed the effect of E2F1 alone, causing severe growth retardation (Figure 7A, $P<0.05$ ), high levels of apoptosis (Figure 7C, $P<0.05$ ), and reduced migration (Figure 7D, $P<0.05$ ) and invasive ability (Figure 7E, $P<0.05$ ) as compared to the control and mock cells, but had the same effect as E2F1 in promoting G1-S progression (Figure 7B, $P<0.05$ ). E2F1 siRNA and miR-519d inhibitor co-transfection partly counteracted the effects of silencing E2F1 on cell proliferation, the cell cycle, apoptosis, migration, and invasion, although the cells still exhibited slower growth (Figure 7F, $P<0.05$ ), G1 arrest (Figure 7G, $P<0.05$ ), increased apoptosis (Figure $7 \mathrm{H}$, $P<0.05$ ), decreased migration (Figure 7I, $P<0.05$ ) and invasive ability (Figure 7J, $P<0.05$ ) as compared with the control and mock cells.

These results demonstrate that miR-519d plays a central role in E2F1 promotion of ovarian carcinoma cell proliferation, apoptosis, and cell migration and invasion, but not on the cell cycle.

\section{Effects of E2F1 and RhoC co-transfection on ovarian carcinoma cells}

A2780 and OVCAR3 cells were co-transfected with E2F1 plasmid and RhoC siRNA or with E2F1 siRNA and RhoC plasmid. Cell functional assays were performed to analyze the effects on A2780 and OVCAR3 cell proliferation, cycle, apoptosis, migration, and invasion. E2F1 plasmid and RhoC siRNA cotransfection reversed the effect of E2F1 alone, causing severe growth retardation (Figure $8 \mathrm{~A}, P<0.05$ ), higher levels of apoptosis (Figure 8C, $P<0.05$ ), and reduced cell migration (Figure $8 \mathrm{D}, P<0.05$ ) and invasive ability (Figure $8 \mathrm{E}, P<0.05$ ), but had the same effect in promoting G1-S progression (Figure $8 \mathrm{~B}, P<0.05$ ) when compared with the control and mock cells. E2F1 siRNA and $\mathrm{RhoC}$ plasmid co-transfection partly counteracted the effects of E2F1 silencing on cell proliferation, the cell cycle, apoptosis, and cell migration and invasion, although the cells still exhibited slower growth (Figure 8F, $P<0.05$ ), G1 arrest (Figure 8G, $P<0.05$ ), increased apoptosis (Figure $8 \mathrm{H}, P<0.05$ ), and decreased migration (Figure 8I, $P<0.05$ ) and invasive ability (Figure 8J, $P<0.05)$ when compared with the control and mock cells.

These results demonstrate that RhoC plays a central role in the oncogenic regulation by $\mathrm{E} 2 \mathrm{~F} 1 / \mathrm{miR}-519 \mathrm{~d}$ on ovarian carcinoma cell proliferation, apoptosis, migration, and invasion, but not on the cell cycle. 


\section{DISCUSSION}

According to the most recent National Comprehensive Cancer Network (NCCN) guidelines, epithelial ovarian cancer is grouped into type I ovarian cancer (mostly originating from the ovary) and type II ovarian cancer (mostly originating from the oviduct) [31]. We compared $E 2 F 1$ expression levels in 59 cases of type I tumors and 17 normal ovarian tissues, and $E 2 F 1$ expression was significantly elevated in the ovarian carcinoma tissues

A

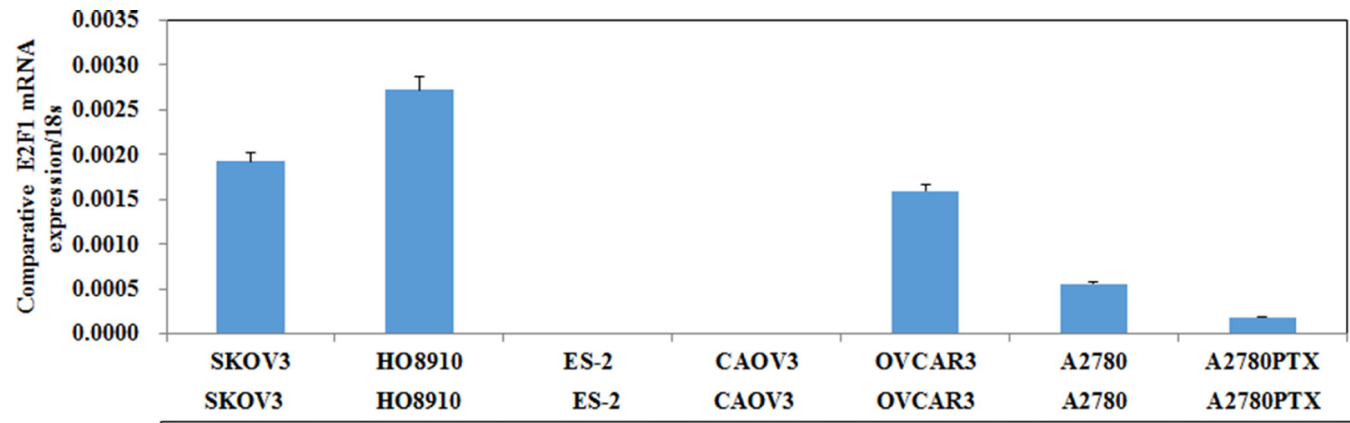

B

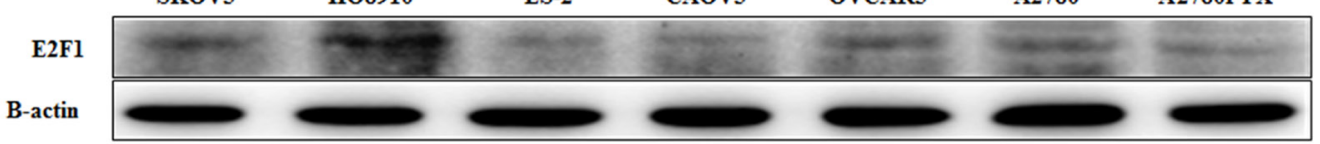

C
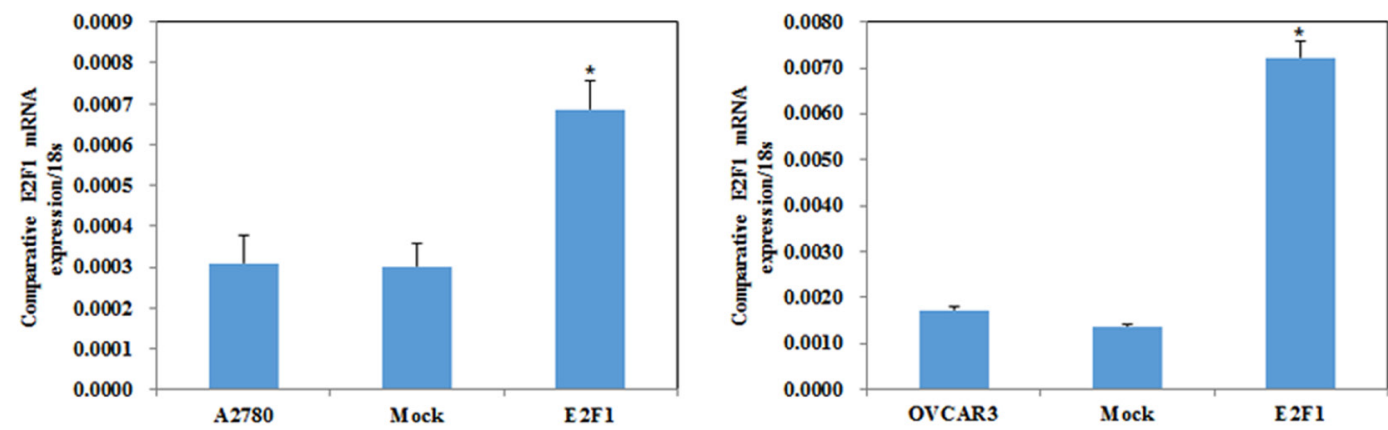

D
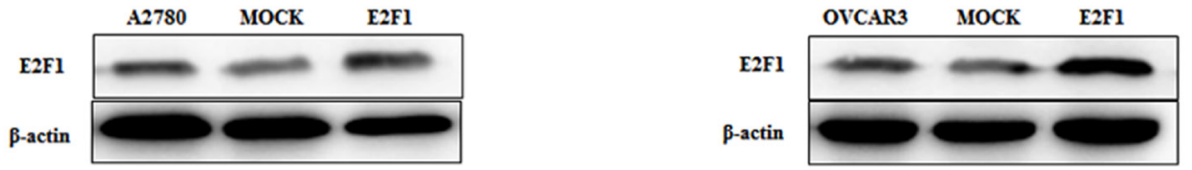

$\mathbf{E}$
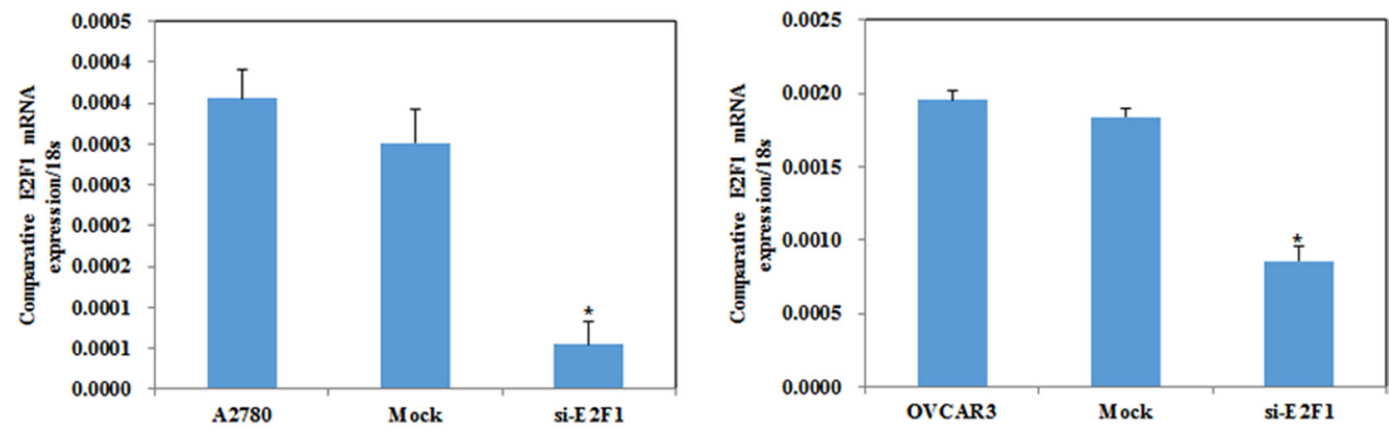

$\mathbf{F}$
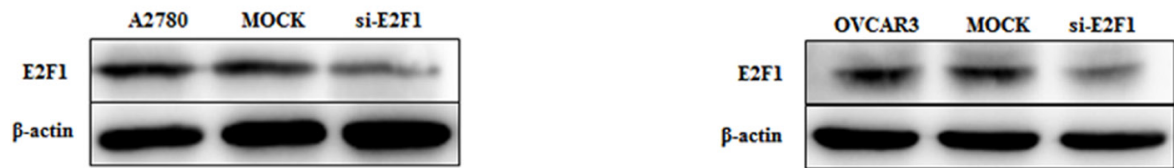

Figure 2: E2F1 expression in ovarian cancer cell lines. E2F1 mRNA and protein expression levels among ovarian cancer cell lines SKOV3, HO8910, ES-2, CAOVR3, OVCAR3, A2780 and A2780PTX were examined (A and B). Transfection of A2780 and OVCAR3 cells with the E2F-1 plasmid results in increased E2F-1 (C) mRNA and (D) protein expression, while silencing of E2F-1 reduces (E) mRNA and $(\mathbf{F})$ protein expression. 
A
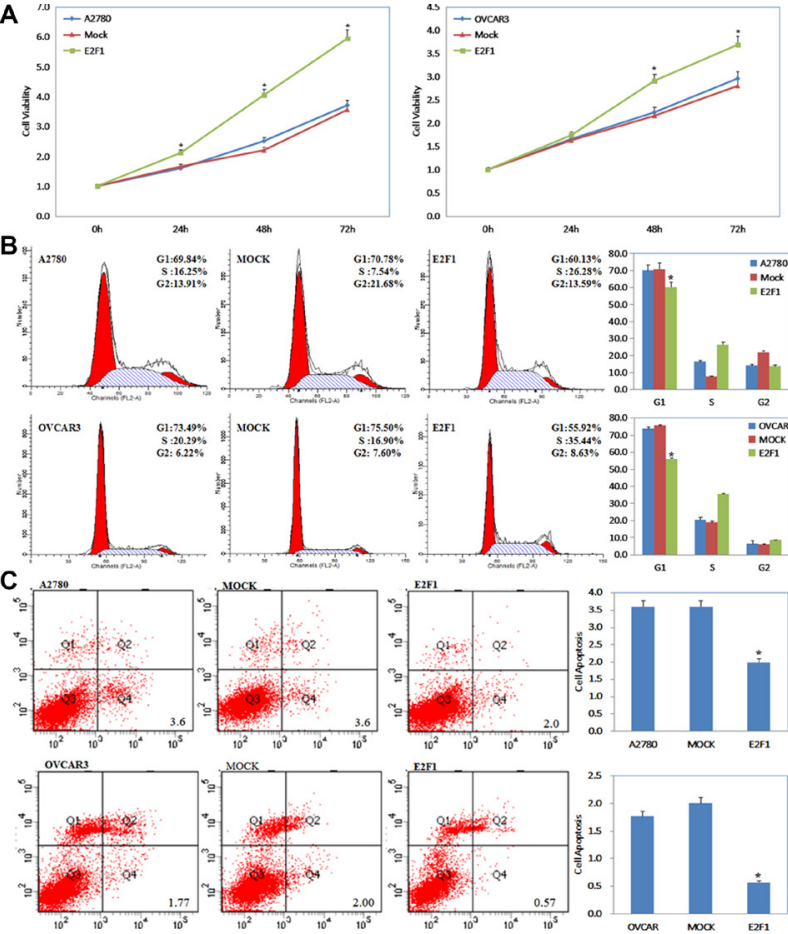

F
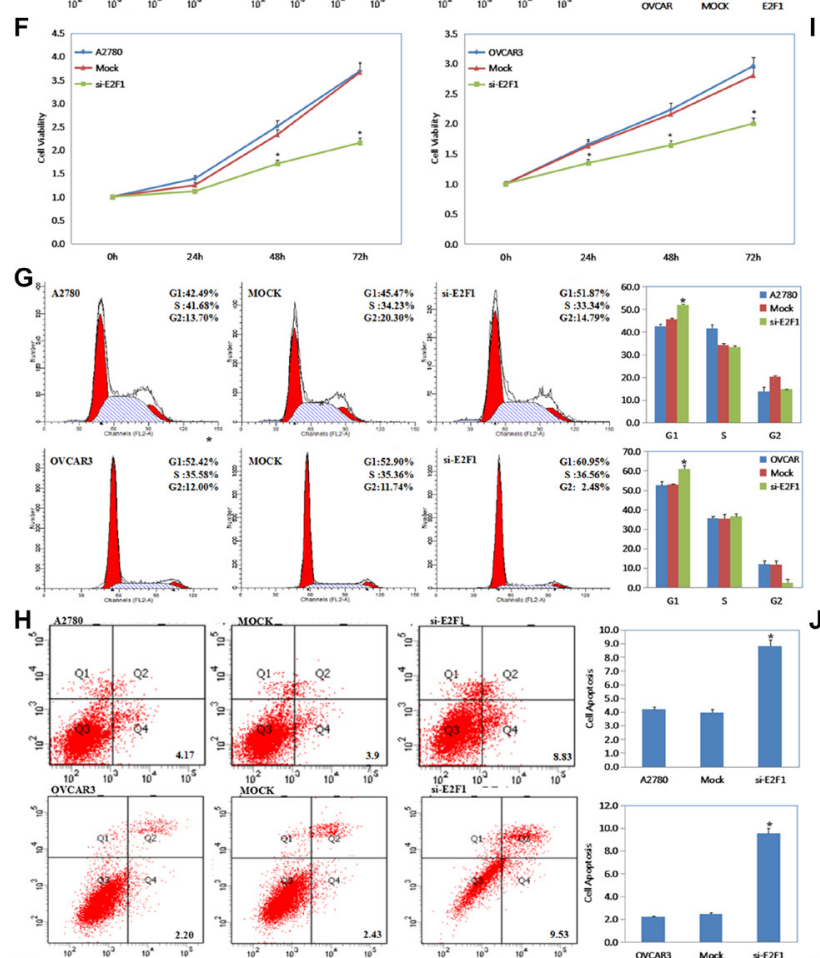

K
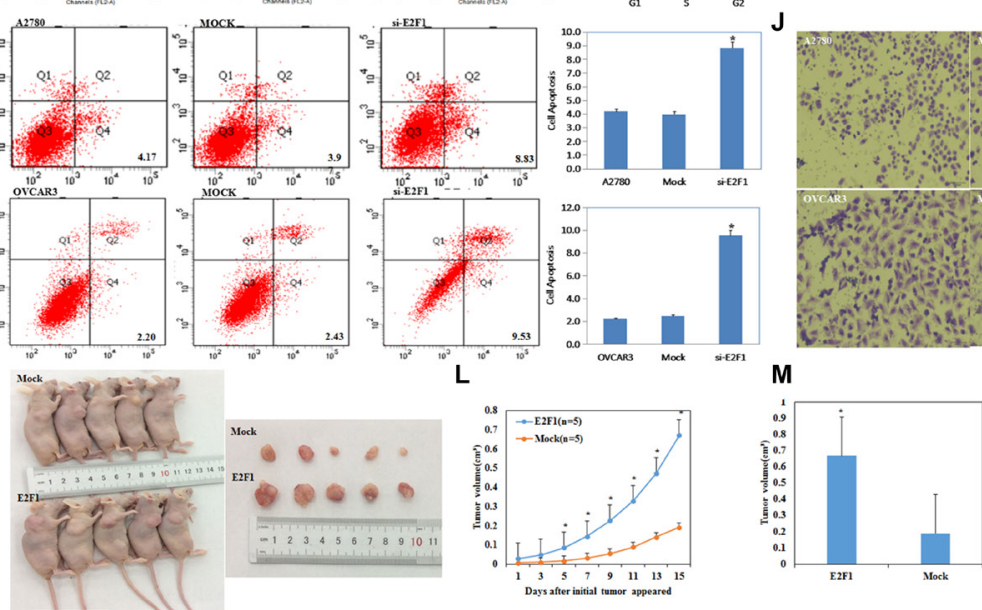

.
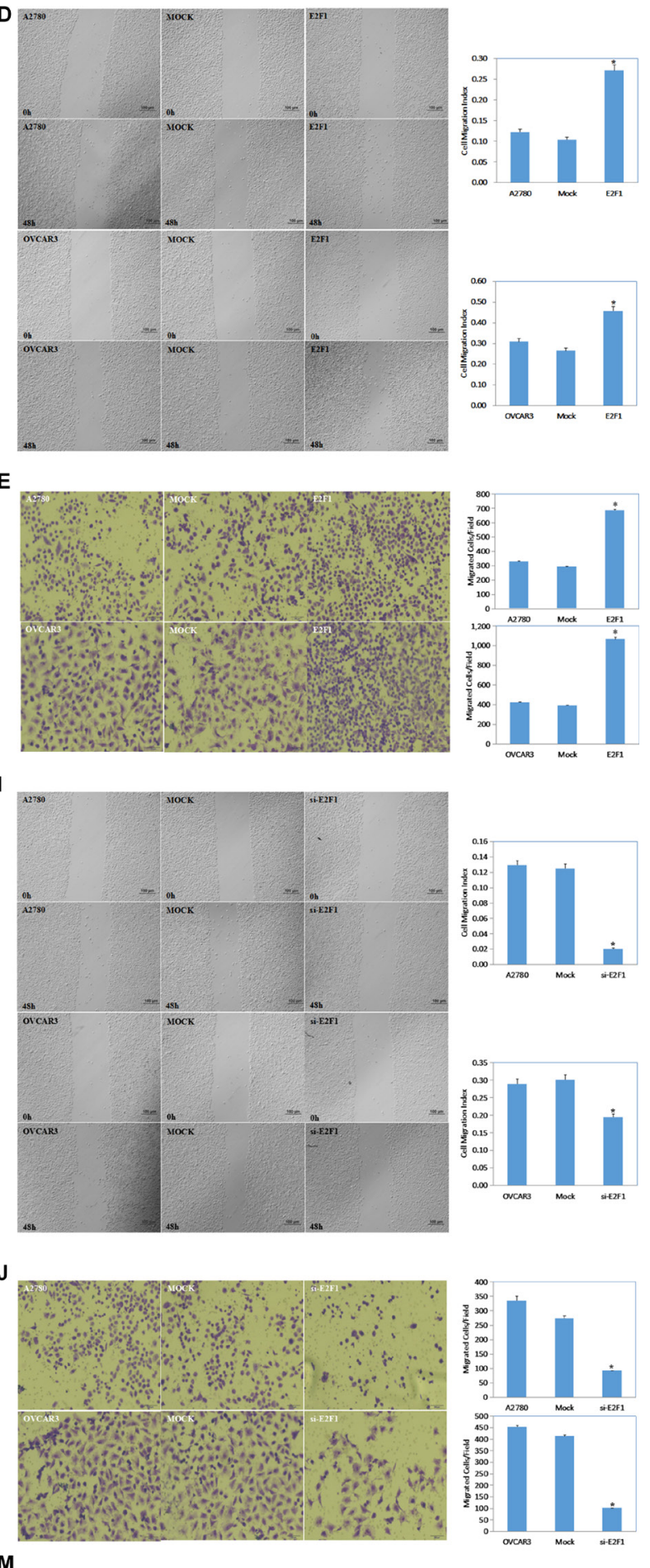

Figure 3: Effects of E2F1 on ovarian carcinoma in vitro and in vivo. Overexpression of E2F-1 (A) increased the rate of growth, (B) promoted G1/S progression, (C) decreased levels of apoptosis, (D) increased migration and (E) invasion ability. Knockdown of E2F1 exhibit significantly (F) decreased growth, (G) increased G1 arrest and (H) increased apoptosis, (I) lower migration and (J) invasion ability. Nude mice injected with cells stably expressing E2F-1 showed a dramatic increase in tumor size (K) and tumor xenograft $(\mathbf{L})$ growth and (M) volum in vivo. Results are representative of three separate experiments; data are expressed as the mean \pm standard deviation. * $p<0.05$. 
A

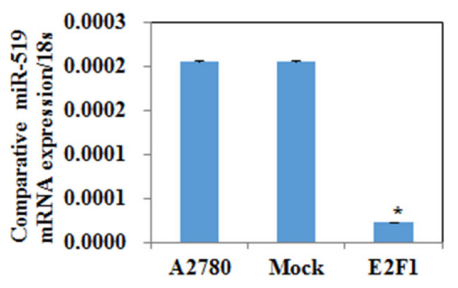

B

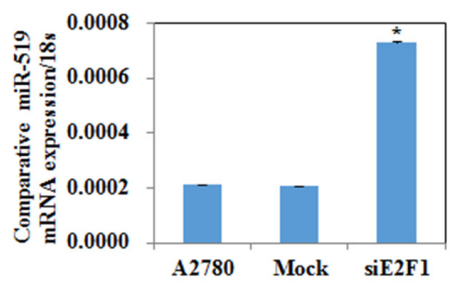

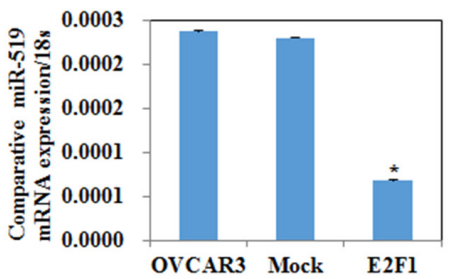

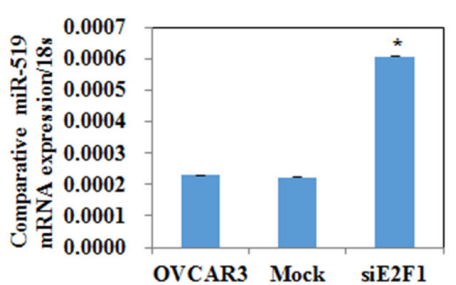

$\mathbf{C}$

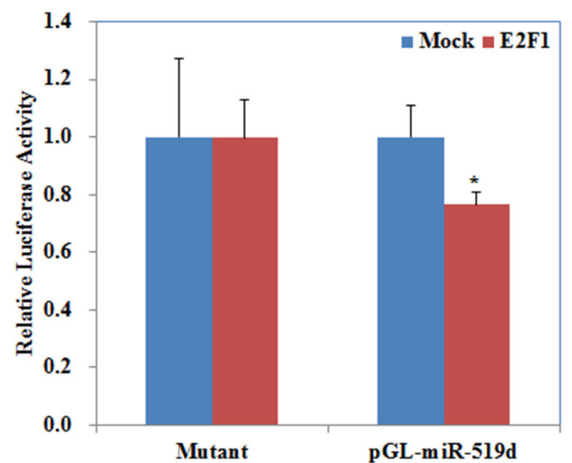

D
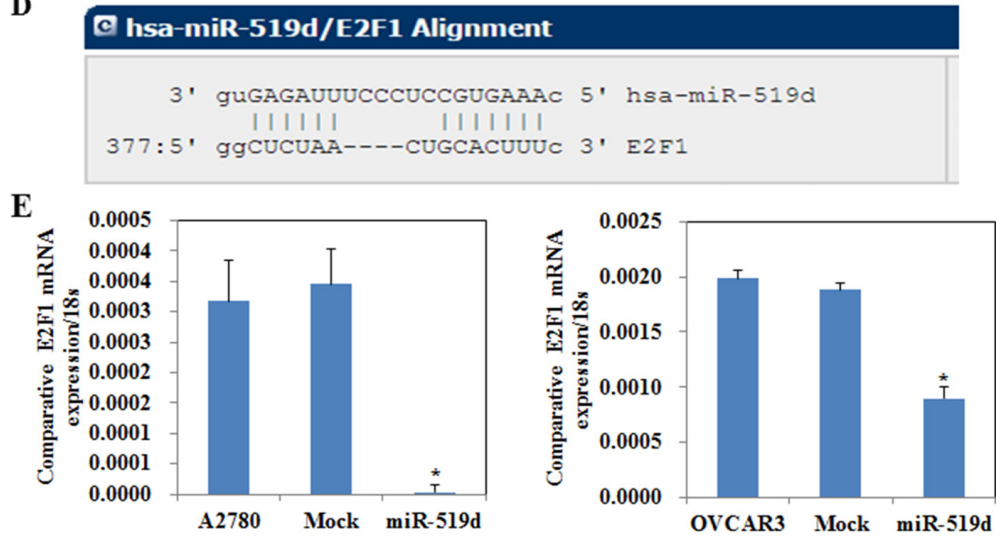

$\mathbf{F}$

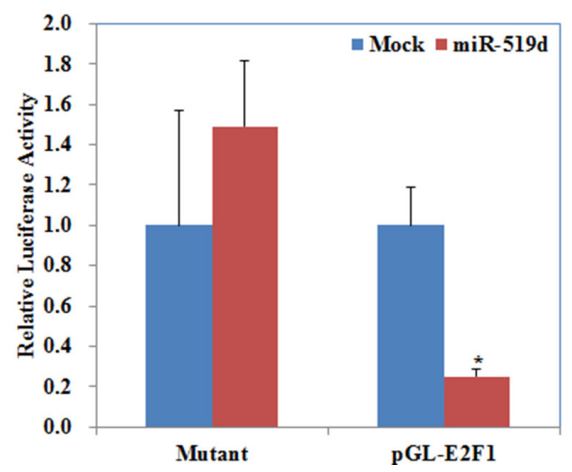

Figure 4: E2F1 downregulated miR-519d directly, and miR-519d downregulated E2F1 directly. (A) Overexpression of E2F-1 represses miR-519d mRNA expression. (B) Silencing of E2F-1 promotes miR-519d mRNA expression. (C) Luciferase reporter assays confirm that miR-519d is the target of E2F-1. (D) The microRNA.org website predicted that the E2F1 mRNA 3' untranslated region (3' UTR) contained miR-519d binding sites. (E) Overexpression of miR-519d represses E2F-1 mRNA expression. (F) Luciferase reporter assays confirm that E2F-1 is the target of miR-519d. * $p<0.05$. 
and was positively associated with FIGO stage I-II and III-IV disease. We also compared E2F1 expression levels in 96 cases of type II tumors and 23 fallopian tube tissues, and $E 2 F 1$ expression was also significantly elevated in the ovarian carcinoma tissues. The finding is consistent with the study by Suh and colleagues [27]. We found that E2F1 promoted ovarian carcinoma cell proliferation, G1-S progression, survival, migration, and invasion in vitro and

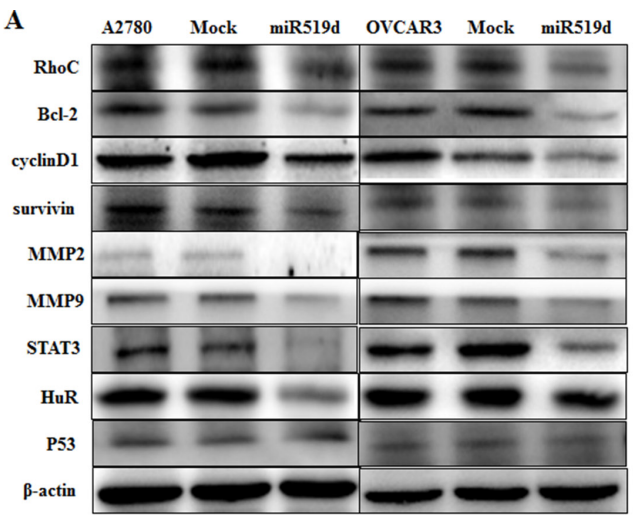

B

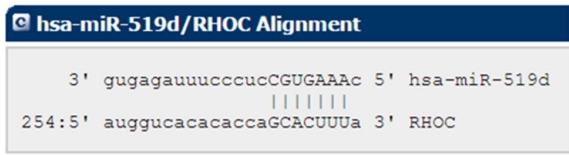

D

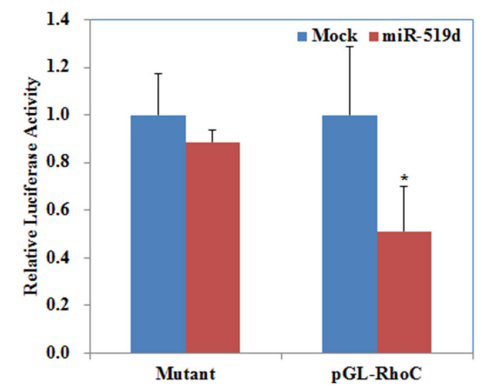

F

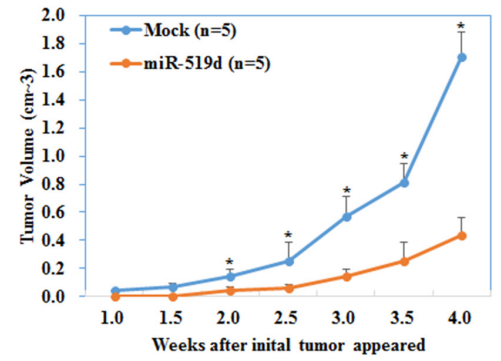

$\mathbf{G}$

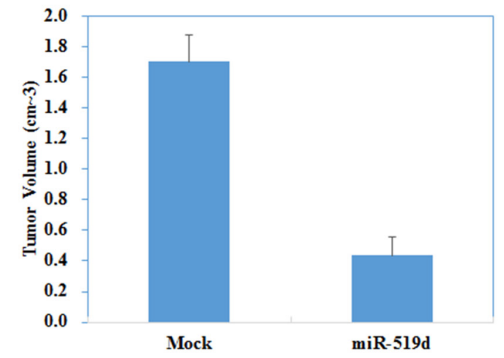

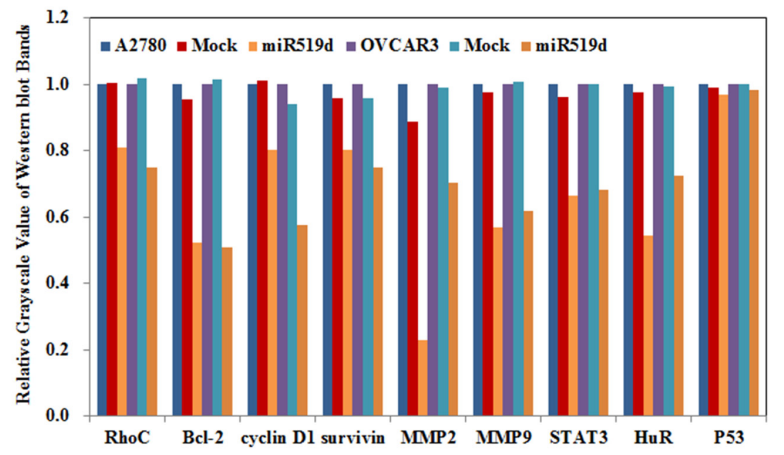

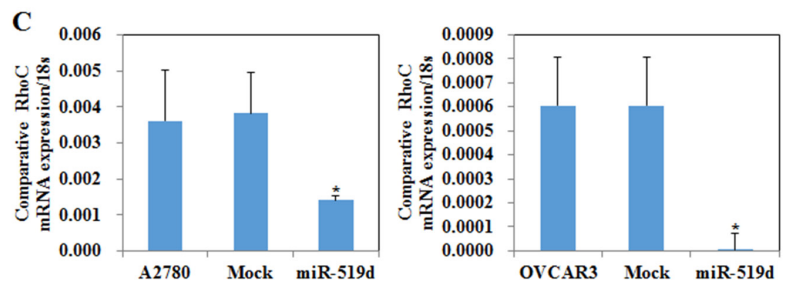

$\mathbf{E}$
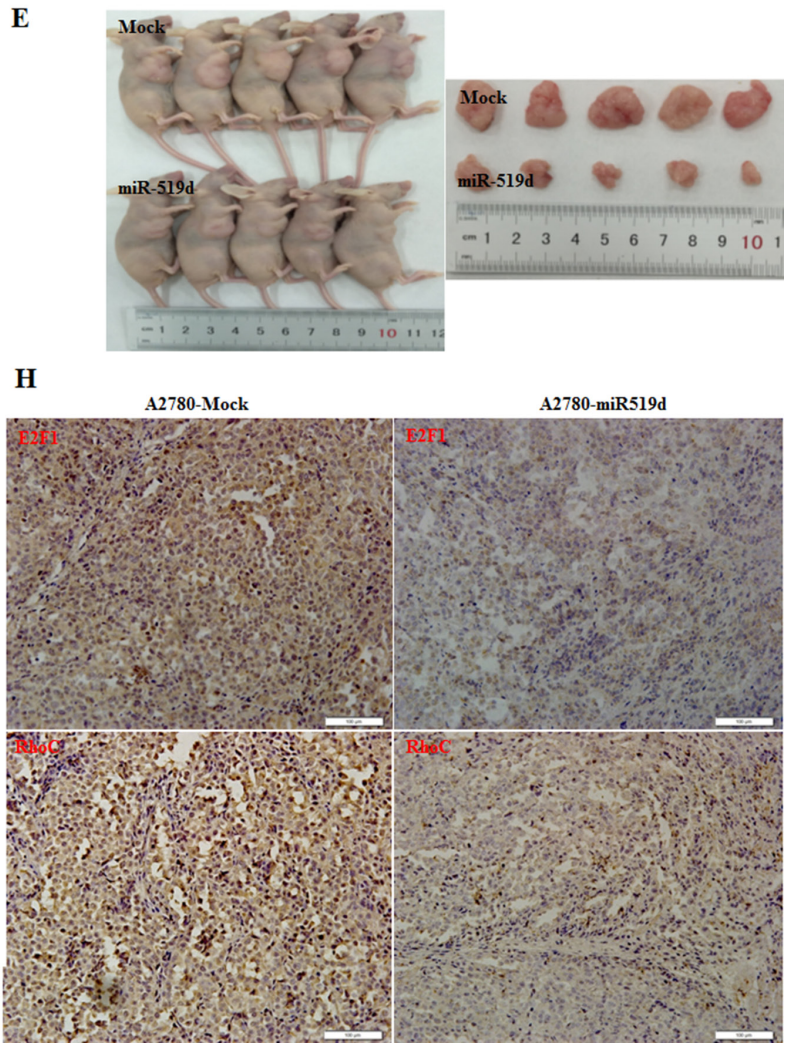

Figure 5: MiR-519d inhibits ovarian carcinoma and downregulates RhoC directly. (A) miR-519d transfection in A2780 and OVCAR3 cells downregulated RhoC, Bcl-2, cyclin D1, survivin, MMP2, MMP9, STAT3, and HuR expression. No changes were observed in p53 expression. (B) The sequence in the 3'UTR of RhoC complementary to the miRNA-519d seed region suggests that RhoC is a direct target of miR-519d. (C) miR-519d transfection reduces mRNA expression of RhoC. (D) Dual luciferase reporter assay indicated that miR-519d directly targets RhoC by binding its 3'UTR. Nude mice injected with cells stably expressing miR-519d showed a (E) dramatic reduction in tumor size and tumor xenograft $(\mathbf{F})$ growth and $(\mathbf{G})$ volumn. $(\mathbf{H})$ miR-519d overexpression downregulates E2F1 and RhoC expression in tumor xenografts in vivo. * $p<0.05$. 

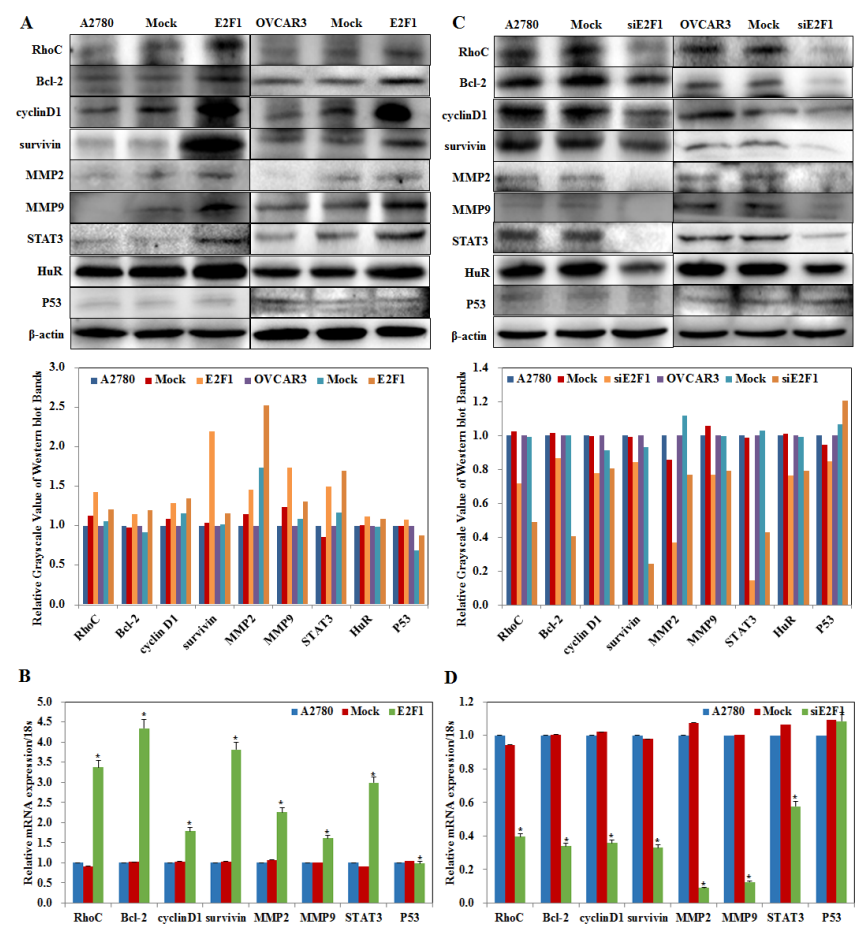

D
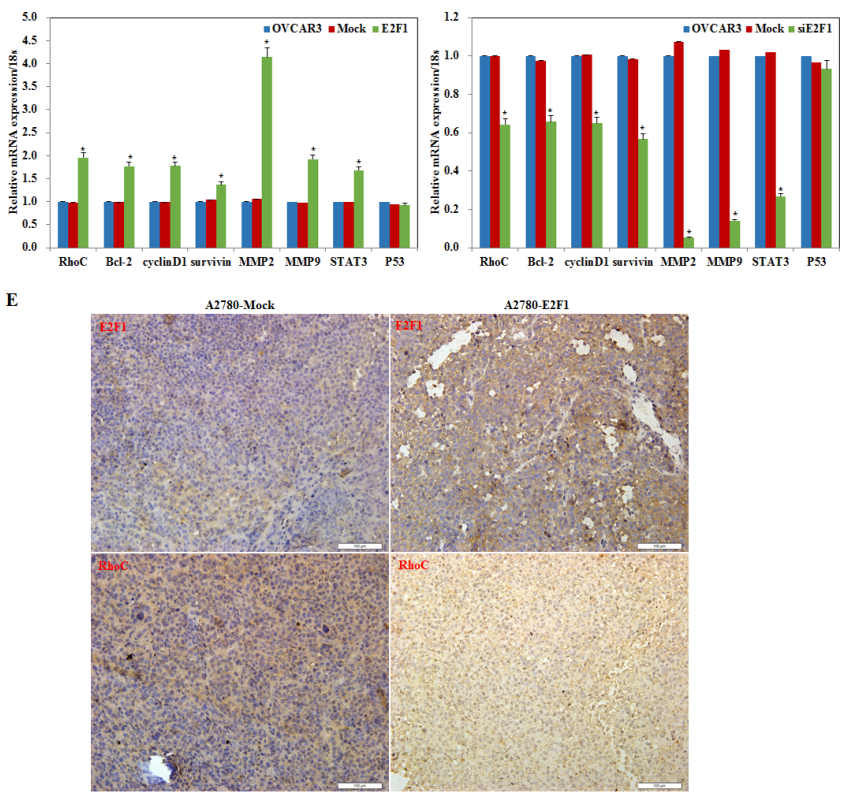

$\mathbf{F}$

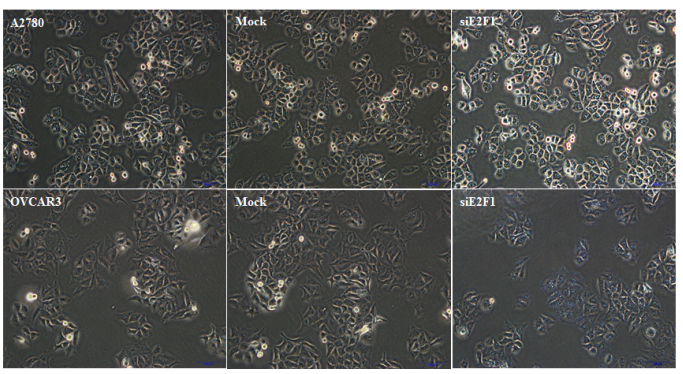

Figure 6: Effects of E2F1 on ovarian carcinoma cell genotype. Overexpression of E2F-1 increases RhoC, Bcl-2, cyclin D1, survivin, MMP2, MMP9, STAT3, and HuR (A) protein and (B) mRNA expression. Silencing of E2F-1 decreases RhoC, Bcl-2, cyclin D1, survivin, MMP2, MMP9, STAT3, and HuR (C) protein and (D) mRNA expression. However, no significant differences were found in P53. (E) E2F-1-injected nude mice up-regulation of E2F-1 and RhoC expression in tumor xenografts. (F) silencing E2F1 increased SA- $\beta$-gal (senescence-associate $\beta$-galactosidase) activity and triggered senescence. ${ }^{*} p<0.05$ 

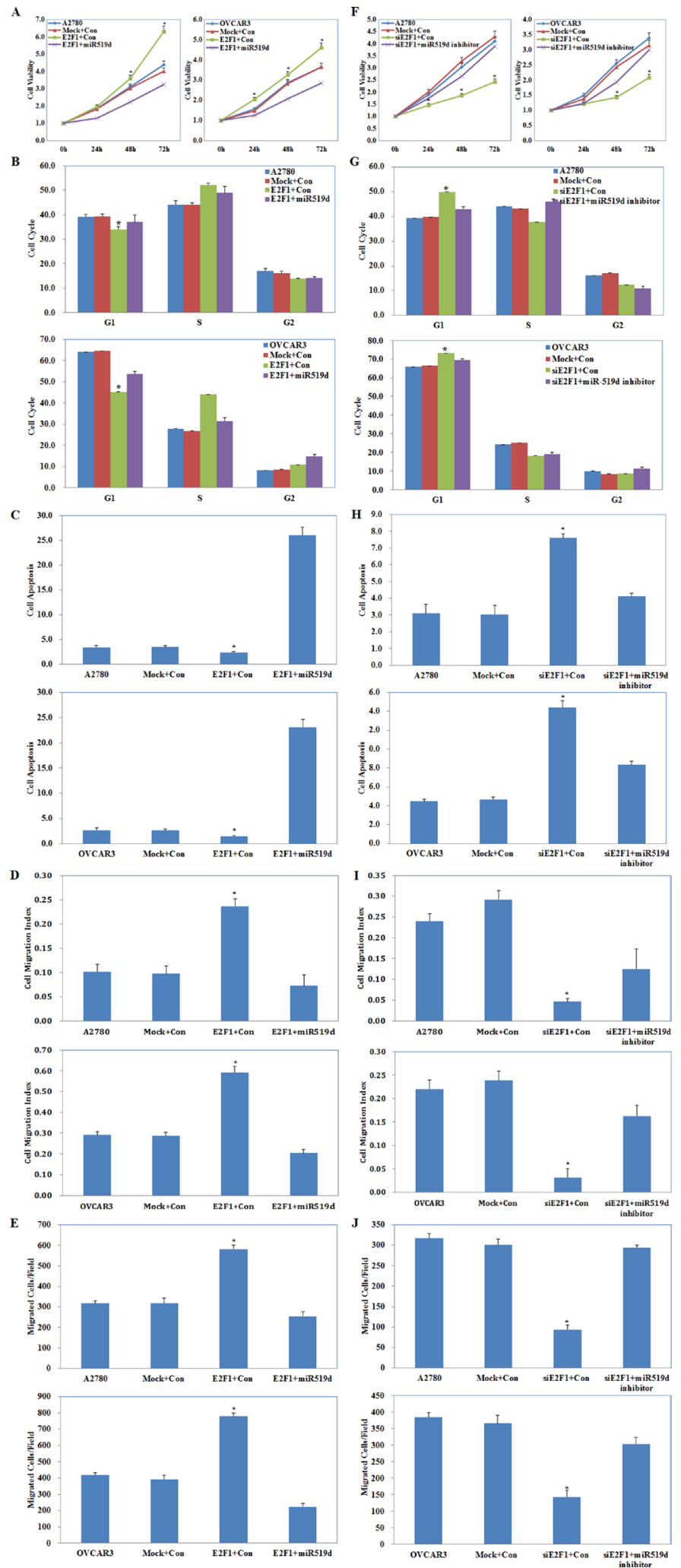

Figure 7: Effects of E2F1 and miR-519d co-transfection on ovarian carcinoma cells. E2F1 plasmid and miR-519d mimic co-transfection (Mock+Con stands for E2F1-mutant plus miR-519d contorl, E2F1+Con stands for E2F1 plasmid plus miR-519d control ) caused (A) severe growth retardation, (B) promoting G1-S progression, (C) high levels of apoptosis, and reduced (D) migration and (E) invasive ability. E2F1 siRNA and miR-519d inhibitor co-transfection (Mock+Con stands for siE2F1-mutant plus miR-519d inhibitor contorl, siE2F1+Con stands for E2F1 siRNA plus miR-519d inhibitor control ) exhibited (F) slower growth, (G) G1 arrest, (H) increased apoptosis, (I) decreased migration and (J) invasive ability. ${ }^{*} p<0.05$. See Supplementary Figure 1. 

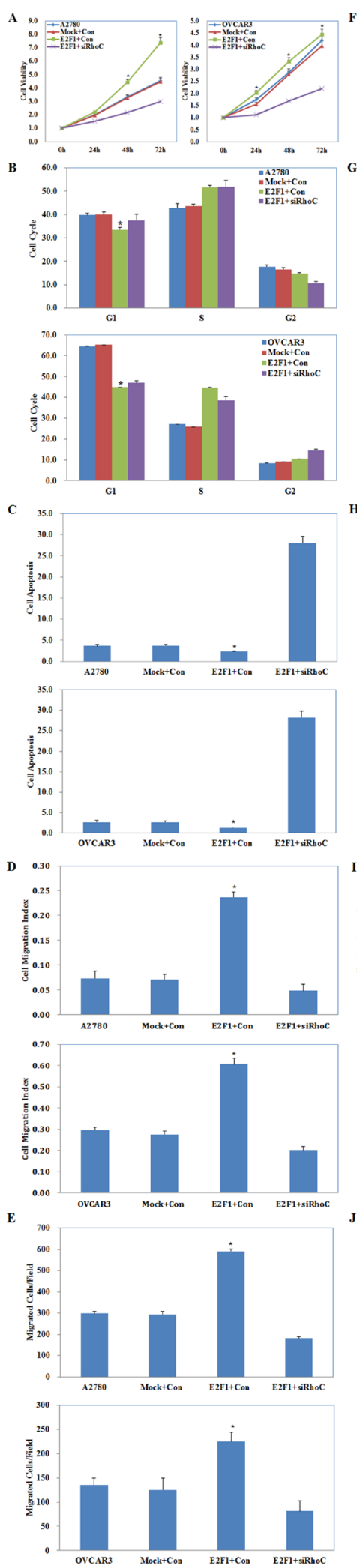
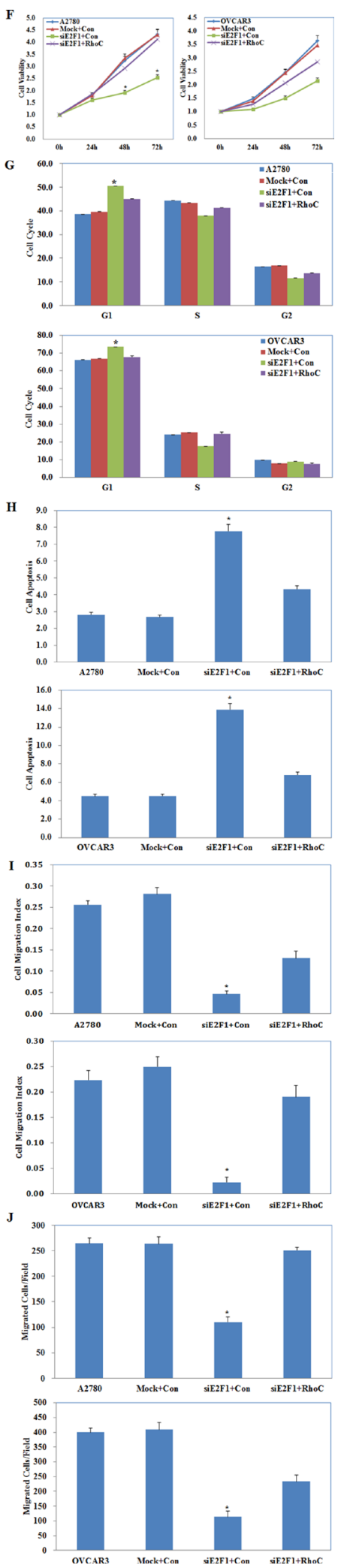

Figure 8: Effects of E2F1 and RhoC co-transfection on ovarian carcinoma cells. E2F1 plasmid and RhoC siRNA cotransfection (Mock+Con stands for E2F1-mutant plus siRhoC contorl, E2F1+Con stands for E2F1 plasmid plus siRhoC control) caused (A) severe growth retardation, (B) promoting G1-S progression, (C) higher levels of apoptosis, and (D) reduced cell migration and (E) invasive ability. E2F1 siRNA and RhoC plasmid co-transfection (Mock+Con stands for siE2F1-mutant plus RhoC contorl, siE2F1+Con stands for E2F1 siRNA plus RhoC control ) exhibited (F) slower growth, $(\mathbf{G})$ G1 arrest, $(\mathbf{H})$ increased apoptosis, and decreased (I) migration and (J) invasive ability as compared to the control and mock cells. ${ }^{*} p<0.05$. See Supplementary Figure 2. 
promoted ovarian carcinoma tumorigenesis and tumor growth in vivo. We also observed that E2F1 increased Bcl-2, cyclin D1, survivin, MMP2, and MMP9 expression in ovarian carcinoma, but did not alter p53 expression. These results are similar to the oncogenic role of E2F1 in small cell lung cancer [28] and clear cell renal cell carcinoma [29], but differ from the suppressive effect of E2F1 in gastric cancer [17-19] and Hodgkin lymphoma [25]. Our findings suggest that E2F1 functions as an oncogene in ovarian carcinoma in part by upregulating Bcl-2, cyclin D1, survivin, MMP2, and MMP9 expression.

To explore the underlying molecular mechanism of the oncogenic effects of E2F1 on ovarian carcinoma, we focused on microRNAs (miRNAs). MiRNAs are small, non-coding, single-stranded, and evolutionarily conserved RNAs that regulate gene expression by binding directly to complementary sites in the $3^{\prime}$ UTR of target mRNAs; the process plays a crucial role in tumor development and progression [32-33]. Previous studies have proved that transcription factors act together with miRNAs in regulating the target genes [34].

The dual luciferase reporter assay confirmed the prediction that the $m i R-519 d$ promoter sequence contains an E2F1 binding site. E2F1 overexpression suppressed $m i R-519 d$ mRNA expression, proving that E2F1 targets the $m i R-519 d$ promoter directly to decrease its expression. MiR-519d belongs to the chromosome 19 miRNA cluster (C19MC), and acts as a tumor suppressor in breast cancer, chondrosarcoma, osteosarcoma, and hepatocellular carcinoma [35-38], and it is significantly downregulated in ovarian cancer cell lines and tissues [39]. MiR-519d decreased ovarian cancer cell proliferation and sensitized ovarian cancer cells to cisplatin-induced cell death [40]. We conclude that miR-519d has the same suppressive effects on ovarian carcinoma based on the significantly decreased tumor size and growth in the nude mouse xenograft model. MiR-519d suppresses trophoblast cell invasion and migration by downregulating MMP2 [41], suppresses breast cancer by inhibiting STAT3 expression [35], and inhibits tumor metastasis and MMP2 expression in chondrosarcoma and osteosarcoma [36-37]. MiR-519d reduces cell proliferation and inhibits tumorigenesis largely by decreasing the levels of the RNA-binding protein HuR to trigger senescence in ovarian carcinoma cells [42-44]. We found that miR519d transfection decreased MMP2, MMP9, STAT3, and $H u R$ expression in ovarian carcinoma cells; at the same time, E2F1 increased the expression of these genes. We found that silencing $E 2 F 1$ triggered senescence in ovarian carcinoma cells, supporting the premise that E2F1 targets $m i R-519 d$ directly, decreasing its expression. We cotransfected ovarian carcinoma cells with E2F1 plasmid and miR-519d mimic, and found that miR-519d greatly reversed the effect of E2F1, revealing that miR-519d plays a central role in the oncogenic effects of E2F1 on ovarian carcinogenesis and development.
We found that $\mathrm{RhoC}$ is a putative and direct target of miR-519d, which the dual luciferase reporter assay confirmed. We observed that miR-519d transfection decreased RhoC expression and that $E 2 F 1$ overexpression increased $\mathrm{RhoC}$ expression in ovarian carcinoma cell lines; RhoC expression was decreased in miR-519d tumor xenograft tissue and was increased in E2F1 tumor xenograft tissue when compared with their respective controls. RhoC is a small $\mathrm{G}$ protein/guanosine triphosphatase closely involved in tumor invasion and metastasis [45-47], and could serve as a good biomarker of ovarian carcinoma differentiation and progression [48-49]. We found that E2F1 plasmid and RhoC siRNA co-transfection greatly reversed the oncogenic role of E2F1 in ovarian carcinoma cell phenotype, revealing that RhoC plays a central role in the oncogenic regulation of E2F1/miR-519d on ovarian carcinogenesis and development. The above findings demonstrate that E2F1 promotes ovarian carcinoma by directly targeting miR-519d, suppressing it, which in turn targets RhoC expression, downregulating it. Conversely, miR-519d mimic decreased $E 2 F 1$ expression. The prediction that miR-519d would target the E2F1 mRNA 3' UTR was in agreement with the results of the dual luciferase reporter assay. Furthermore, E2F1 expression was lower in the miR-519d xenograft group, proving that miR-519d also targets $E 2 F 1$ to downregulate its expression. These findings indicate an E2F1-miR-519d direct repressive regulatory loop.

In the E2F family of transcription factors, E2F2, $\mathrm{E} 2 \mathrm{~F} 3, \mathrm{E} 2 \mathrm{~F} 4$, and E2F8 expression is increased and may play oncogenic roles in ovarian carcinoma [26, 30, 50-51], and exert the same effects as E2F1. We searched target prediction websites and found that in addition to E2F1, the miR-519d promoter also contains E2F4 binding sites. Taken together, we hypothesize that E2F4 could have the same oncogenic effects as E2F1 on ovarian carcinoma by suppressing miR-519d. However, further research is needed to confirm this.

In conclusion, our study identifies a novel molecular mechanism for E2F1, whereby it targets miR519d to upregulate RhoC, Bcl-2, cyclin D1, survivin, MMP2, MMP9, STAT3 and HuR expression, promoting tumorigenesis and progression in ovarian carcinoma. The E2F1/miR-519d/RhoC signaling pathway is of significant importance and shows promise as a target for diagnosing and treating ovarian carcinoma.

\section{MATERIALS AND METHODS}

\section{Ovarian carcinoma specimens}

According to the latest NCCN guidelines, ovarian cancer were grouped into type I ovarian cancer (most origin from ovaries) and type II ovarian cancer (most origin from oviducts). Consisting of type I tumors 59 cases 
and type II tumors 96 cases, 17 normal ovarian tissues cases and 23 fallopian tube tissues cases were collected from patients undergoing surgical resection at the Department of Gynecology of the First Affiliated Hospital of China Medical University (Shenyang, Liaoning, China) between 2003 and 2014. The tumor specimens were microscopically confirmed by pathologists. None of the patients had received preoperative chemotherapy or radiotherapy. Informed consent was obtained from all subjects, the study was approved by the China Medical University Ethics Committee, and all specimens were handled and made anonymous according to ethical and legal standards. The average age at surgery was 54.3 years (range, 18-76 years). Each ovarian carcinoma specimen was evaluated according to the 2014 FIGO staging system. The histological architecture of ovarian carcinoma was defined in terms of World Health Organization classification.

\section{Cell culture and transfection}

The ovarian carcinoma cell lines OVCAR3 (serous cystic adenocarcinoma) and A2780 (serous cystic adenocarcinoma) were cultured in RPMI 1640 (HyClone, Logan, USA), while A2780 cells were cultured in DMEM (HyClone). Both mediums were supplemented with 10\% fetal bovine serum (FBS), $100 \mathrm{U} / \mathrm{mL}$ penicillin, and $100 \mu \mathrm{g} / \mathrm{mL}$ streptomycin. All cell lines were maintained at a temperature of $37^{\circ} \mathrm{C}$ and a humidified atmosphere of $5 \%$ CO2. The medium was changed every two days for optimized culture conditions. Transfections were performed using Lipofectamine 2000 transfection reagent according to the manufacture's protocol. The sequence of siRNA targeting E2F-1 was: 5'-CGCUAUGAGACCUCACUG-3'. The sequence of the miR-519d mimic was: 5'-CAAAGTGCCTCCCTTTAGAGTG-3'. The target sequences of the RhoC siRNA were $5^{\prime}$-GUGCCUUUGG CUACCUUGAdTdT-3' (sense) and 5'-UCAAGGUA GCCAAAGGCACdTdT-3' (anti-sense).

\section{MTT assay}

Ninety-six well plates were seeded with $3 \times 103$ cells per well. At designated time points following transfection ( $0 \mathrm{~h}, 24 \mathrm{~h}, 48 \mathrm{~h}$, and $72 \mathrm{~h}$ ), $20 \mu \mathrm{L}$ of $5 \mathrm{mg} / \mathrm{mL}$ MTT (Sigma,USA) was added into every well and cells incubated at $37^{\circ} \mathrm{C}$ for 4 hours. The liquid was then removed and $150 \mu \mathrm{L}$ of dimethylsulfoxide (DMSO, Sigma, USA) added to dissolve the precipitated formazan. Following shaking for $10 \mathrm{~min}$, the optical density (OD) was measured at $490 \mathrm{~nm}$ on a microplate spectrophotometer (Bio-Tek Instruments, Winooski, USA).

\section{Cell cycle analysis}

More than $1 \times 104$ cells were trypsinized, collected, washed twice with phosphate buffered saline (PBS), and fixed in $70 \%$ ethanol at $-20^{\circ} \mathrm{C}$ for at least $12 \mathrm{~h}$. The cells were washed twice with PBS and incubated with $400 \mu \mathrm{L}$ RNase $(0.25 \mathrm{mg} / \mathrm{mL})$ at $37^{\circ} \mathrm{C}$ for $1 \mathrm{~h}$, then resuspended in $100 \mu \mathrm{L}$ Propidium Iodide(PI, KeyGen, NanJing China) and incubated at $4{ }^{\circ} \mathrm{C}$ in the dark for $30 \mathrm{~min}$. The PI cell cycle profile was detected by flow cytometry.

\section{Cell apoptosis assay}

Cells were harvested at $1500 \mathrm{rpm}$ for $5 \mathrm{~min}$ and washed twice with cold PBS. They were then resuspended in a mix of $50 \mu \mathrm{L}$ binding buffer, $5 \mu \mathrm{L}$ annexin V-FITC and $5 \mu \mathrm{L}$ PI (KeyGen, China). Samples were gently vortexed and incubated in the dark for $15 \mathrm{~min}$ at room temperature. Two hundred microliters of binding buffer was added to each tube and samples were examined by flow cytometer within $1 \mathrm{~h}$.

\section{Wound healing assay}

Cells were seeded into 6-well plates and cultured for approximately $24 \mathrm{~h}$ to reach $80 \%$ confluence in the presence of mitomycin C(10 ug/ml, Sigma, USA). The monolayer was then scratched with a $200 \mu \mathrm{L}$ pipette tip to create a wound. The 6-well plates were washed twice with PBS, and cells cultured in FBS-free medium. Cells were transfected with the miRNA or siRNA (or controls) at the same time. Prior to the wound healing assay, the width of each wound was examined by microscope and photographed using Image $\mathrm{J}$ software (National Institutes of Health, Bethesda, USA) at $0 \mathrm{~h}, 24 \mathrm{~h}$ and $48 \mathrm{~h}$ after wounding. Cell migration was measured by subtracting the wound width at $24 \mathrm{~h}$ or $48 \mathrm{~h}$ from that at $0 \mathrm{~h}$.

\section{Cell invasion assay}

Cell invasion assays were performed using Transwell chambers (24-well inserts; $8 \mu \mathrm{m}$-pore size; BD Bioscience, San Jose, CA, USA) pre-coated with $40 \mu \mathrm{L}$ of Matrigel basement membrane matrix (Matrigel at a dilution of $1: 10$ ) incubated for $4 \mathrm{~h}$ at $37^{\circ} \mathrm{C}$ in $5 \%$ $\mathrm{CO} 2$. Two hundred microliters of serum-free medium containing $5 \times 104$ cells/well of transfected or nontransfected cells were placed in the upper chamber in the presence of mitomycin C (10 ug/ml, Sigma, USA), and the lower chambers filled with $600 \mu \mathrm{L}$ of the same complete medium. The plates were incumanuscripting cells at the bottom of the upper chamber were washed twice with PBS. Cells on the underside of the filters were examined and counted using an Olympus fluorescence microscope (Tokyo, Japan). Cells were counted three times, and each experiment was repeated in triplicate.

\section{Cell senescence}

Cells were washed once with PBS, $1 \mathrm{ml}$ of $\beta$-galactosidase staining fixative was added and fixed at 
room temperature for 15 minutes, Then cells were washed three times with PBS for 3 minutes each, after that $1 \mathrm{ml}$ of working solution was added to each well, incubated overnight at $37^{\circ} \mathrm{C}$, then observed cells under ordinary light microscope.

\section{Real-time RT-PCR}

Total RNA extraction from ovarian carcinoma cell lines and ovarian tissues was performed with $1 \mathrm{~mL}$ TRIzol reagent (Takara, Shiga, Japan) and the total RNA was reverse-transcribed to complementary DNA (cDNA) using the avian myeloblastosis virus reverse transcriptase and random primers (Takara, Shiga, Japan) according to the manufacturer's instructions. Real-time PCR amplification of the cDNA was performed in $20 \mu \mathrm{L}$ reactions according to the SYBR Premix Ex Taq II kit (Takara, Shiga, Japan) protocol; 18S rRNA was used as the internal control. Hairpin-it microRNA Normalization RT-PCR Quantitation (GenePharma) was used to check E2F-1. The oligonucleotide primers for PCR were based on GenBank sequences. The primers used for E2F-1 and GAPDH were as follows: E2F-1 forward, 5-CCATCCAGGAAAAGGTGTGAA-3 and reverse, 5-AGCGCTTGGTGGTCAGATTC-3'.

\section{Western blotting}

Cells were harvested and lysed with ice-cold lysis buffer (Sigma, USA) and protein concentration determined using a protein assay kit (Bio-Rad Laboratories, Hercules, USA). Denatured proteins $(100 \mu \mathrm{g})$ were separated on $10 \%$ sodium dodecyl sulfate (SDS)-polyacrylamide gels, transferred to Hybond membranes (Amersham, Munich, Germany), and blocked overnight in 5\% skimmed milk in Tris-buffered saline with Tween 20 (TBST). For immunoblotting, the membrane was incubated with antibodies against E2F-1, RhoC (1:300, Santa Cruz Biotechnology, Santa Cruz, USA), p53, caspase 3, stat3, Bcl-2, cyclin D1, matrix metalloproteinase (MMP) 2 and MMP9 (1:300, Bioss,BeiJing, China), HuR(proteintech, Chicago, USA). The membranes were then rinsed with TBST and incubated with anti-mouse or anti-rabbit IgG antibodies conjugated to horseradish peroxidase (1:5000; Dako, Carpinteria, USA) for $2 \mathrm{~h}$. Bands were visualized on X-ray film (Fuji film, Tokyo, Japan) using Image Quant LAS 4000 (Fuji film) and ECL Plus detection reagents (Santa Cruz Biotechnology). $\beta$-actin (ZSGB-Bio,BeiJing, China) was used as a loading control.

\section{Dual luciferase reporter assay}

The plasmid were designated pGL3-RhoC, pGL3miR-519d and pGL3-E2F1. The pGL3-RhoC mutant plasmid, pGL3-miR-519d mutant plasmid and pGL3-E2F1 mutant plasmid containing nucleotide mutations in the predicted binding site based on the the website searching in GenBank and inserted into the downstream region of the firefly luciferase reporter (Promega, Madison, WI, USA). HEK293T Cells were seeded at $1 \times 105$ cells per well in 24-well plates, and cultured until $70 \%$ confluent. Cells were then co-transfected with the the pGL3-plasmid and relate plasmid or mimic ( $50 \mathrm{nM}$, Ribobio Biotechnology); pGL3-mutant, plasmid-mutant and control (400 ng, Promega) using Lipofectamine 2000. After 48 hours cells were lysed using cell lysis buffer (Cell Signaling, Boston, USA) and luciferase activity was measured using the Dual Luciferase Reporter Assay System (Promega BioSciences, San Luis Obispo, USA) according to the manufacturer's instructions. The luciferase activities were normalized to that of Renilla luciferase. The results were expressed as the means \pm SD of at least three independent experiments.

\section{In vivo xenografts}

Female 4-5 week-old, 18 20 g BALB/c nude mice were obtained from Vital River Laboratories (Beijing, China) and housed in a SPF grade environment. Subcutaneous tumor xenografts were established via injection of $1 \times 10^{7}$ A2780 cells suspended in $200 \mu \mathrm{L}$ PBS with (E2F-1 group or miR-519d group) or without (mock group) LV-hsa-E2F-1 transfection or LV-hsa-miR519d transfection (Genechem, Shanghai, China) directly hypodermic in. All animal research protocols were performed following the National Institutes of Health Guide for the Care and Use of Laboratory Animals and were approved by the China Medical University Animal Care and Use Committee.

\section{Immunohistochemistry}

Consecutive tissue sections were deparaffinized with xylene, rehydrated with alcohol, and subjected to antigen retrieval by heating in target retrieval solution (Dako) for $15 \mathrm{~min}$ in a microwave oven (Oriental Rotor). The sections were quenched with $3 \%$ hydrogen peroxide for $20 \mathrm{~min}$ to block endogenous peroxidase activity. Nonspecific binding was prevented by adding $5 \%$ bovine serum albumin for $5 \mathrm{~min}$. The sections were incubated at $4^{\circ} \mathrm{C}$ overnight with anti-E2F1 or anti-RhoC antibodies, and then incubated with HRP-conjugated anti-rabbit antibodies (Dako) for $2 \mathrm{~h}$. After each treatment, the slides were washed three times with TBST for $5 \mathrm{~min}$, and the binding sites were visualized with 3, 3'-diaminobenzidine. After counterstaining with Mayer's hematoxylin, the sections were dehydrated, cleared and mounted. Negative controls were prepared by omitting the primary antibody.

\section{Statistical analysis}

Statistical evaluation was performed using the Spearman correlation test to analyze the rank data and 
the Mann-Whitney $U$ test to differentiate the means of different groups. Cox's proportional hazards model was employed for multivariate analysis. A $p$-value of $<0.05$ was considered statistically significant. SPSS 17.0 (SPSS, Chicago, IL, USA) software was employed to analyze all data.

\section{ACKNOWLEDGMENTS AND FUNDING}

This work was supported by grants from the Liaoning Science and Technology Grant (2013021077), and the Natural Scientific Foundation of China (81202049, 81472440, 81472502, 81602266).

\section{CONFLICTS OF INTEREST}

The authors declare that they have no conflicts of interest with the contents of this article.

\section{Authors' contributions}

Yang Zhao conceived the study, and analyzed interpretation. Xiu-bo Sang, Li-li Wang, Dan-dan Wu, Shuo Chen, Bo-liang Liu carried out the experiments and analyzed the data. Zhi-Hong Zong gave many good suggestions about data processing and manuscript. All authors read and approved the final manuscript.

\section{REFERENCES}

1. Cannistra SA. Cancer of the ovary. N Eng J Med. 2004; 351:2519-29.

2. Siegel R, Naishadham D, Jemal A. Cancer statistics, 2012. CA Cancer J Clin. 2012; 62:10-29. doi: 10.3322/ caac. 20138 .

3. Armstrong D. Update on treatment options for newly diagnosed ovarian cancer. Clin Adv Hematol Oncol. 2010; 8:675-8.

4. Siegel R, Naishadham D, Jemal A. Cancer statistics, 2013. CA Cancer J Clin. 2013; 63:11-30. doi: 10.3322/ caac. 21166.

5. Parkin DM, Bray F, Ferlay J, Pisani P. Global cancer statistics, 2002. CA Cancer J Clin. 2005; 55:74-108.

6. Nelson MA, Reynolds SH, Rao UN, Goulet AC, Feng Y, Beas A, Honchak B, Averill J, Lowry DT, Senft JR, Jefferson AM, Johnson RC, Sargent LM. Increased gene copy number of the transcription factor E2F1 in malignant melanoma. Cancer Biol Ther. 2006; 5:407-12.

7. Tarangelo A, Lo N, Teng R, Kim E, Le L, Watson D, Furth EE, Raman P, Ehmer U, Viatour P. Recruitment of Pontin/Reptin by E2f1 amplifies E2f transcriptional response during cancer progression. Nat Commun. 2015; 6:10028. doi: 10.1038/ncomms 10028 .

8. Han S, Park K, Bae BN, Kim KH, Kim HJ, Kim YD, Kim HY. E2F1 expression is related with the poor survival of lymph node-positive breast cancer patients treated with fluorouracil, doxorubicin and cyclophosphamide. Breast Cancer Res Treat. 2003; 82:11-16.

9. Tang YA, Lin RK, Tsai YT, Hsu HS, Yang YC, Chen CY, Wang YC. MDM2 overexpression deregulates the transcriptional control of $\mathrm{RB} / \mathrm{E} 2 \mathrm{~F}$ leading to DNA methyltransferase 3A overexpression in lung cancer. Clin Cancer Res. 2012; 18:4325-33. doi: 10.1158/1078-0432. CCR-11-2617.

10. Viatour P, Sage J. Newly identified aspects of tumor suppression by RB. Dis Model Mech. 2011; 4:581-5. doi: 10.1242/dmm.008060.

11. Stevens C, La Thangue NB. E2F and cell cycle control: a double-edged sword. Arch Biochem Biophysics. 2003; 412:157-69.

12. La Thangue NB. The yin and yang of E2F-1: balancing life and death. Nat Cell Biol. 2003; 5:587-9.

13. Dimova DK, Dyson NJ. The E2F transcriptional network: old acquaintances with new faces. Oncogene. 2005; 24:2810-26.

14. Lin Z, Ren N, Jiang Y, Xu W, Shi Y, Liu G. AdenovirusMediated E2F-1 Gene Transfer Augments GemcitabineInduced Apoptosis in Human Colon Cancer Cells. Clin Lab. 2015; 61:1435-44.

15. Yin YW, Jin HJ, Zhao W, Gao B, Fang J, Wei J, Zhang DD, Zhang J, Fang D. The Histone Acetyltransferase GCN5 Expression Is Elevated and Regulated by c-Myc and E2F1 Transcription Factors in Human Colon Cancer. Gene Expr. 2015; 16:187-96. doi: 10.3727/105221615X14399878166230.

16. Jian $\mathrm{T}$, Chen Y. Regulatory mechanisms of transcription factors and target genes on gastric cancer by bioinformatics method. Hepatogastroenterology. 2015; 62:524-8.

17. Wei WY, Yan LH, Wang XT, Li L, Cao WL, Zhang XS, Zhan ZX, Yu H, Xie YB, Xiao Q. E2F-1 overexpression inhibits human gastric cancer MGC-803 cell growth in vivo. World J Gastroenterol. 2015; 21:491-501. doi: 10.3748/ wjg.v21.i2.491.

18. Wang XT, Xie YB, Xiao Q. Lentivirus-mediated RNA interference targeting E2F-1 inhibits human gastric cancer MGC-803 cell growth in vivo. Exp Mol Med. 2011; 43: 638-45. doi: 10.3858/emm.2011.43.11.072.

19. Xie Y, Wang C, Li L, Ma Y, Yin Y, Xiao Q. Overexpression of E2F-1 inhibits progression of gastric cancer in vitro. Cell Biol Int. 2009; 33:640-9. doi: 10.1016/j. cellbi.2009.02.015.

20. Lee SR, Roh YG, Kim SK, Lee JS, Seol SY, Lee HH, Kim WT, Kim WJ, Heo J, Cha HJ, Kang TH, Chung JW, Chu IS, et al. Activation of EZH2 and SUZ12 Regulated by E2F1 Predicts the Disease Progression and Aggressive Characteristics of Bladder Cancer. Clin Cancer Res. 2015; 21:5391-403. doi: 10.1158/1078-0432.

21. Lee JS, Leem SH, Lee SY, Kim SC, Park ES, Kim SB, Kim SK, Kim YJ, Kim WJ, Chu IS. Expression signature of E2F1 and its associated genes predict superficial to 
invasive progression of bladder tumors. J Clin Oncol. 2010; 28:2660-7. doi: 10.1200/JCO.2009.25.0977.

22. Alla V, Engelmann D, Niemetz A, Pahnke J, Schmidt A, Kunz M, Emmrich S, Steder M, Koczan D, Pützer BM. E2F1 in melanoma progression and metastasis. J Natl Cancer Inst. 2010; 102:127-33. doi: 10.1093/jnci/djp458.

23. Gorgoulis VG, Zacharatos P, Mariatos G, Kotsinas A, Bouda M, Kletsas D, Asimacopoulos PJ, Agnantis N, Kittas C, Papavassiliou AG. Transcription factor E2F-1 acts as a growth-promoting factor and is associated with adverse prognosis in non-small cell lung carcinomas. J Pathol. 2002; 198:142-56.

24. Eymin B, Gazzeri S, Brambilla C, Brambilla E. Distinct pattern of E2F1 expression in human lung tumours: E2F1 is upregulated in small cell lung carcinoma. Oncogene. 2001; 20:1678-87.

25. Georgiadi EC, Dimtsas GS, Vassilakopoulos TP, Pangalis GA, Kittas C, Doussis-Anagnostopoulou IA. Functional p53 can modulate the relationship between E2F-1 expression and tumor kinetics in Hodgkin lymphoma. Leuk Lymphoma. 2015; 56:748-54. doi: 10.3109/10428194.2014.930850.

26. Zhan L, Zhang Y, Wang W, Song E, Fan Y, Wei B. E2F1: a promising regulator in ovarian carcinoma. Tumour Biol. 2016; 37:2823-31. doi:10.1007/s13277-015-4770-7.

27. Suh DS, Yoon MS, Choi KU, Kim JY. Significance of E2F-1 overexpression in epithelial ovarian cancer. Int J Gynecol Cancer. 2008; 18:492-8.

28. Li Z, Guo Y, Jiang H, Zhang T, Jin C, Young CY, Yuan H. Differential regulation of MMPs by E2F1, Sp1 and NFkappa B controls the small cell lung cancer invasive phenotype. BMC Cancer. 2014; 14:276. doi: 10.1186/14712407-14-276.

29. Ma X1, Gao Y, Fan Y, Ni D, Zhang Y, Chen W, Zhang P, Song E, Huang Q, Ai Q, Li H, Wang B, Zheng T, et al. Overexpression of E2F1 Promotes Tumor Malignancy And Correlates with TNM Stages in Clear Cell Renal Cell Carcinoma. PLoS One. 2013; 8:e73436. doi: 10.1371/ journal.pone.0073436.

30. Reimer D1, Sadr S, Wiedemair A, Stadlmann S, Concin N, Hofstetter G, Müller-Holzner E, Marth C, Zeimet AG. Clinical relevance of E2F family members in ovarian cancer--an evaluation in a training set of 77 patients. Clin Cancer Res. 2007; 13:144-51.

31. Morgan RJ Jr, Armstrong DK, Alvarez RD, BakkumGamez JN, Behbakht K, Chen LM, Copeland L, Crispens MA, DeRosa M, Dorigo O, Gershenson DM, Gray HJ, Hakam A, et al. Ovarian Cancer, Version 1.2016, NCCN Clinical Practice Guidelines in Oncology. J Natl Compr Canc Netw. 2016; 14:1134-63.

32. Bentwich I1, Avniel A, Karov Y, Aharonov R, Gilad S, Barad O, Barzilai A, Einat P, Einav U, Meiri E, Sharon E, Spector Y, Bentwich Z. Identification of hundreds of conserved and nonconserved human microRNAs. Nat Genet. 2005; 37:766-70.
33. Abba ML, Patil N, Leupold JH, Allgayer H. MicroRNA Regulation of Epithelial to Mesenchymal Transition. J Clin Med. 2016; 5:E8. doi: 10.3390/jcm5010008.

34. Petrocca F, Visone R, Onelli MR, Shah MH, Nicoloso MS, de Martino I, Iliopoulos D, Pilozzi E, Liu CG, Negrini M, Cavazzini L, Volinia S, Alder H, et al. E2F1-regulated microRNAs impair TGFbeta-dependent cell-cycle arrest and apoptosis in gastric cancer. Cancer Cell. 2008;13: 272-86. doi: 10.1016/j.ccr.2008.02.013.

35. Deng X, Zhao Y, Wang B. miR-519d-mediated downregulation of STAT3 suppresses breast cancer progression. Oncol Rep. 2015; 34:2188-94. doi: 10.3892/ or.2015.4160.

36. Tsai CH, Tsai HC, Huang HN, Hung CH, Hsu CJ, Fong YC, Hsu HC, Huang YL, Tang CH. Resistin promotes tumor metastasis by down-regulation of miR-519d through the AMPK/p38 signaling pathway in human chondrosarcoma cells. Oncotarget. 2015; 6:258-70. doi: 10.18632/ oncotarget. 2724.

37. Tsai HC, Su HL, Huang CY, Fong YC, Hsu CJ, Tang $\mathrm{CH}$. CTGF increases matrix metalloproteinases expression and subsequently promotes tumor metastasis in human osteosarcoma through down-regulating miR519d. Oncotarget. 2014; 5:3800-12. doi: 10.18632/ oncotarget.1998.

38. Hou YY, Cao WW, Li L, Li SP, Liu T, Wan HY, Liu M, Li X, Tang H. MicroRNA-519d targets MKi67 and suppresses cell growth in the hepatocellular carcinoma cell line QGY-7703. Cancer Lett. 2011; 307:182-90. doi: 10.1016/j.canlet.2011.04.002.

39. Zhang L1, Volinia S, Bonome T, Calin GA, Greshock J, Yang N, Liu CG, Giannakakis A, Alexiou P, Hasegawa K, Johnstone CN, Megraw MS, Adams S, et al. Genomic and epigenetic alterations deregulate microRNA expression in human epithelial ovarian cancer. Proc Natl Acad Sci USA. 2008; 105:7004-9. doi: 10.1073/pnas.0801615105.

40. Pang Y, Mao H, Shen L, Zhao Z, Liu R, Liu P. MiR-519d represses ovarian cancer cell proliferation and enhances cisplatin-mediated cytotoxicity in vitro by targeting XIAP. Onco Targets Ther. 2014; 7:587-97. doi: 10.2147/OTT. S60289.

41. Ding J, Huang F, Wu G, Han T, Xu F, Weng D, Wu C, Zhang X, Yao Y, Zhu X. MiR-519d-3p suppresses invasion and migration of trophoblast cells via targeting MMP-2. PLoS One. 2015; 10:e0120321. doi: 10.1371/journal. pone. 0120321 .

42. Abdelmohsen K, Srikantan S, Kuwano Y, Gorospe M. miR-519 reduces cell proliferation by lowering RNAbinding protein HuR levels. Proc Natl Acad Sci USA. 2008; 105:20297-302. doi: 10.1073/pnas.0809376106.

43. Abdelmohsen K, Kim MM, Srikantan S, Mercken EM, Brennan SE, Wilson GM, Cabo Rd, Gorospe M. miR-519 suppresses tumor growth by reducing HuR levels. Cell Cycle. 2010; 9:1354-9. 
44. Ristimäki A. Tumor suppressor effect of the microRNA miR-519 is mediated via the mRNA-binding protein HuR. Cell Cycle. 2010; 9:1234.

45. Vega FM, Fruhwirth G, Ng T, Ridley AJ. RhoA and RhoC have distinct roles in migration and invasion by acting through different targets. J Cell Biol. 2011; 193:655-65. doi: $10.1083 /$ jcb.201011038.

46. Hakem A, Sanchez-Sweatman O, You-Ten A, Duncan G, Wakeham A, Khokha R, Mak TW. RhoC is dispensable for embryogenesis and tumor initiation but essential for metastasis. Genes Dev. 2005; 19:1974-9.

47. Clark EA, Golub TR, Lander ES, Hynes RO. Genomic analysis of metastasis reveals an essential role for RhoC. Nature. 2000; 406:532-5.

48. Zhao Y, Zheng HC, Chen S, Gou WF, Xiao LJ, Niu ZF. The role of RhoC in ovarian epithelial carcinoma: a marker for carcinogenesis, progression, prognosis, and target therapy. Gynecol Oncol. 2013; 130:570-8. doi: 10.1016/j. ygyno.2013.06.004.

49. Gou WF, Zhao Y, Lu H, Yang XF, Xiu YL, Zhao S, Liu JM, Zhu ZT, Sun HZ, Liu YP, Xu F, Takano Y, Zheng HC. The role of RhoC in epithelial-to-mesenchymal transition of ovarian carcinoma cells. BMC Cancer. 2014; 14:477. doi: 10.1186/1471-2407-14-477.

50. De Meyer T, Bijsmans IT, Van de Vijver KK, Bekaert S, Oosting J, Van Criekinge W, van Engeland M, Sieben NL. E2Fs mediate a fundamental cell-cycle deregulation in high-grade serous ovarian carcinomas. J Pathol. 2009; 217:14-20. doi: 10.1002/path.2452.

51. Reimer D, Sadr S, Wiedemair A, Concin N, Hofstetter G, Marth C, Zeimet AG. Heterogeneous cross-talk of E2F family members is crucially involved in growth modulatory effects of interferon-gamma and EGF. Cancer Biol Ther. 2006; 5:771-6. 